the principle benefits of the National Programme for IT.

The SCR is one national database, but one that is entirely centred on the needs and choices of individual patients. It is an option that patients may wish to take up to ensure that the clinicians caring for them have the information needed to make safe clinical decisions. It is a health record and there will be no access for police, immigration authorities, or others. As doctors we would not be involved if such access was considered. The rules on the disclosure of copies of clinical information, for example by court order, are unchanged regardless of how the information is held. The principles and standards for the sharing and utilisation of electronic records are set out clearly in the Care Record Guarantee. ${ }^{5}$

It is on this basis that NHS Connecting for Health systems are designed and built; the challenge for the NHS is to use the controls they are provided with professionally.

\section{Mark Davies}

National Clinical Director, NHS Connecting for Health

\section{Simon Eccles}

National Clinical Director,

NHS Connecting for Health

\section{Gillian Braunold}

Clinical Director, SCR and Healthspace

\section{Marlene Winfield}

National Patient Lead, NHS Connecting for Health

\section{Michael Thick}

Chief Clinical Officer, NHS Connecting for Health

\section{REFERENCES}

1. Anderson R. Confidentiality and Connecting for Health. Br J Gen Pract 2008; 58: 75-76.
2. NHS Connecting for Health. Patient choices. www.connectingforhealth.nhs.uk/systemsandservices/inf ogov/confidentiality/choices?searchterm=access+control $s$ (accessed 8 Feb 2008).

3. NHS Connecting for Health. Guidance for managing requests for no Summary Care Record during the period of the early adopter programme.

http://www.nhscarerecords.nhs.uk/nhs/publications/gpg uidance.pdf (accessed 8 Feb 2008).

4. Royal College of General Practitioners. http://www.connectingforhealth.nhs.uk/systemsandservi ces/crs/scr (accessed 11 Feb 2008).

5. NHS Connecting for Health. The Care Record Guarantee Our guarantee for NHS care records in England. www.connectingforhealth.nhs.uk/nigb/crsguarantee/crs guarantee.pdf (accessed 8 Feb 2008)

DOI: 10.3399/bjgp08X277230

\section{ADDRESS FOR CORRESPONDENCE}

\section{Mark Davies}

National Clinical Director,

NHS Connecting for Health,

New Kings Beam House, 22 Upper Ground,

London SE1 9BW.

E-mail:markdavies@nhs.net

\title{
Community-based maternity care in 2008
}

Four papers published in this issue of the journal examine community-based maternity care, a topic that was also scrutinised in the recently-published Maternity Review by the Healthcare Commission, ${ }^{1}$ and the Confidential Enquiry into Maternal and Child Health report Saving Mothers' Lives. ${ }^{2}$ These reports are not comfortable reading for those concerned with the quality of maternity care.

Providing good quality maternity care has three essential elements. First is the careful balancing act needed to work with childbearing women, enabling them to be as healthy and as normal as possible, while also making sure that all potential problems are detected and appropriately addressed. Second is the effective communication needed between the range of community and hospital-based professionals involved. Third is to make sure that families have all the information and support needed at this demanding time. Straightforward as these elements may sound, different professional groups, based in different sectors, and often with different perspectives and priorities, need to work in harmony to deliver them; this is where many of the problems lie. ${ }^{3}$
The overall direction of maternity services policy has been relatively consistent since the 1993 Department of Health report Changing Childbirth. ${ }^{4}$ The majority of care for women experiencing normal pregnancy now takes place in the community - a significant shift from the over-crowded hospital antenatal clinics of the 1970s and 1980s. Women-focused and family-centred care that meets the diverse needs of women in different communities is an important goal; midwifery-led care, continuity of care, and team working by health and related professionals continue to be policy priorities. ${ }^{5,6}$ Home birth and birth in midwiferyled units are seen as appropriate choices for women with uncomplicated pregnancies. ${ }^{6-8}$ The fundamental contribution that maternity care can make to addressing inequalities in health is widely acknowledged. ${ }^{8,9}$

Other policy changes have had an impact, but not always positive. Changes in the wider NHS have contributed to a serious understaffing of community midwifery services in some parts of the country. ${ }^{10}$ Increased awareness of the complexity of women's social and health status, and the introduction of more routine antenatal screening, have led to an increase in workload that has not been met by increased capacity. Health visiting is undergoing another fundamental examination of its role and purpose, ${ }^{11}$ which is likely to have an impact on health visitors' involvement in maternity care. The reorganisation of out-ofhours GP services has contributed to limiting GPs' involvement in intrapartum care even further. Sure Start programmes and Children's Centres, established to offer local services to the most vulnerable families, have caused a major reorganisation of community-based care, and these services are likely to develop further. ${ }^{12}$

A coordinated response to maternity service policy challenges is lacking, as demonstrated by the papers in this issue of the journal, ${ }^{13-15}$ and other sources: pregnant women still routinely attend first to their GP before being referred to the midwife, ${ }^{1}$ continuing the duplication of early pregnancy care services despite the rhetoric of midwifery-led care. We are still however, reading about the neglect of mental health issues, despite the evidence of its' 
fundamental importance. ${ }^{2,13,16,17}$

Antenatal education and postnatal care some of the services most valued by women $^{18}$ - are still sources of concern for women. Inconsistent information and communication around antenatal screening tests seems to be common. ${ }^{15}$ In addition, women still experience a lack of consistent, good quality breastfeeding support despite positive recommendations for change. ${ }^{19-21}$ Midwifery-led units seem to close almost as often as they open, in spite of their potential to offer valuable, low-intervention, local care. ${ }^{8}$ There is a dearth of wholehearted attempts to rearrange care to tackle the persistent and increasing inequalities in health..$^{22}$ The organisation of care still varies from place to place - even from care provider to care provider - in a bewildering way.

There is, of course, good news among the bad. A high percentage of women report that they are satisfied with the care they get $^{23}$ despite the evidence that care needs to be improved. There are shining examples of services that are offering integrated care, appropriate to women's diverse needs. ${ }^{22}$ However, the changes needed to offer this quality of care to all women have not been put in place. Government support for a national maternity strategy, and coordination between Colleges and professional bodies to introduce the education and training needed for staff to move from one way of providing services to another, would of course have helped. But we have encountered ongoing problems that could be addressed by staff choosing to work in a different way.

As one example; our experience suggests that midwives in some localities have encountered difficulties in delivering services from Sure Start programmes and Children's Centres, such as not being able to store equipment or to have dedicated space for their clinics. GPs are not always involved with the changes needed to provide maternity care from these local sites and sometimes are not even aware that changes have taken place. While aiming to improve care, Sure Start programmes and Children's Centres may simply provide another potential source of fragmentation unless midwifery is welcomed as part of their core services, and midwives and GPs are actively involved in finding new ways of working within these settings.
Another example; although midwifery-led units are welcomed by women and midwives, they often encounter problems when hospital staffing takes priority, and when limited financial scrutiny suggests they are not viable. These units could contribute more securely and positively if a caseload workload model was introduced, to enable small groups of midwives to offer continuity of care to women in hospital, birth centre, and home settings (as is current practice in the Albany Birth Centre in London, for example). Birth centres could also be developed as community centres where all women can attend for antenatal and postnatal care and education, breastfeeding support, and drop-in centres to meet other mothers.

A third example; there still seems to be a tug-of-war around care for pregnant women between some GPs and midwives. As well as the inevitable duplication of care and confusion for women and staff, this has the potential to result in delayed screening tests; ${ }^{; 1,24}$ delayed referral to specialists if the midwife has to refer first to the GP; confusion over who communicates test results to women; ${ }^{14}$ and lack of clarity in responsibility for assessing and responding to concerns about women's mental health. ${ }^{13}$ Women need access to a prompt and effective maternity service. To achieve this aim and help address the current confused picture, a robust agreement should be developed between midwives and other primary care professionals regarding the organisation of care and appropriate referral procedures. It would be logical for most women to be offered midwifery-led care from the start, with direct referral pathways for women who need GP or specialist input. Clear channels of communication between all carers and with women should be agreed and seen as a fundamental component of good care.

A step change is needed in the organisation of community-based maternity care. This will need improvements in communication; joint service planning; a proactive approach to services for vulnerable families; and education at undergraduate and postgraduate levels in regard to teamworking and critical issues, such as antenatal and postnatal mental health.

We have seen examples of localities where such developments are working, so it can be done. But it is difficult to know where to start if your practice has not yet made such changes, or your colleagues are unconvinced. One question to consider does your practice have a maternity forum where GPs, midwives, health visitors, Sure Start and other related staff, and childbearing women can exchange knowledge and information? Where they can learn about each others' aspirations and problems, and agree on professional development to address their learning needs? Where joint decisions can be made on who should take the lead for different issues, including antenatal screening, mental health, postnatal care, breastfeeding, methods of enhancing interprofessional communication, and coordination between practice, Children's Centres and hospital? Perhaps in the future a virtual forum could be added, so that such debate can happen online, encouraging input from young people, fathers, and those who only have space to think when the children are asleep and the practice closed.

Such a forum could demonstrate that your practice is already a beacon of good practice, or it could prove to be a learning opportunity for everyone. Either way, it could make a positive contribution to communitybased maternity care in 2008.

\section{Mary J Renfrew}

Professor of Mother and Infant Health,

Department of Health Sciences, University of York

\section{Jacque Gerrard}

Associate Director of Nursing/Head of Midwifery, CWS Division, Calderdale \& Huddersfield NHS Trust

\section{Helen Baston}

Lecturer in Midwifery/Supervisor of Midwives, Department of Health Sciences, University of York

\section{REFERENCES}

1. Healthcare Commission. Briefing note. Key findings of the 2007 Maternity Service Review. 2008

http://www.healthcarecommission.org.uk/_db/_downloa ds/MaternityServicesReviewOrganisationResults_200801 242628.xls (accessed 6 Feb 2008).

2. Confidential Enquiry into Maternal And Child Health Saving mothers' lives: reviewing maternal deaths to make motherhood safer - 2003-2005. The seventh report on confidential enquiries into maternal deaths in the United Kingdom. London: CEMACH, 2007.

3. Marsh G, MJ Renfrew (eds). Community-based maternity care. Oxford: Oxford University Press, 1999.

4. Department of Health. Changing childbirth. Report of the Expert Maternity Group. London: HMSO, 1993.

5. Department of Health. National Service Framework for Children, Young People and Maternity Services. London: The Stationery Office, 2004.

6. Department of Health. Maternity matters: choice, access 
and continuity of care in a safe service. London: TSO, 2007.

7. National Collaborating Centre for Women's and Children's Health. Intrapartum care: care of healthy women and their babies during childbirth. NICE clinical guideline 55. London: RCOG Press, 2007

8. Department of Health. Shribman S. Making it better: for mother and baby - clinical case for change. London: TSO, 2007

9. Department of Health. Review of the health inequalities infant mortality PSA target. London: TSO, 2007.

10. Royal College of Midwives. Refocusing the role of the midwife. Position paper 26. London: RCM, 2006.

11. Department of Health. Facing the future: a review of the role of health visitors. London: TSO, 2007.

12. Department for Children, Schools and Families. Children and young people today: evidence to support the development of the Children's Plan. London: TSO, 2007.

13. Chew-Graham C, Chamberlain E, Turner K, et al. GPs' and health visitor's views on the diagnosis and management of postnatal depression: a qualitative study. Br J Gen Pract 2008; 58: 169-176.

14. Locock L, Kai J. Parents' experiences of universal screening for haemoglobin disorders: implications for practice in a new genetics era. Br J Gen Pract 2008; 58 $161-168$
15. Dormandy E, Gulliford M, Reid EP, et al, and the SHIFT research team. Delay between pregnancy confirmation and sickle cell thalassaemia screening: a population-based cohort study. Br J Gen Pract 2008; 58: 154-159.

16. Daley A, Winter $\mathrm{H}$, Grimmett $\mathrm{C}$, et al. Feasibility of an exercise intervention in depressed women: a pilot randomised controlled trial. Br J Gen Pract 2008; 58 178-183.

17. National Collaborating Centre for Mental Health Antenatal and postnatal mental health: clinical management and service guidance. NICE clinical guideline 45. London: RCOG Press, 2007.

18. Redshaw M, Rowe R, Hockley C, Brocklehurst P. Recorded delivery: a national survey of women's experience of maternity care. Oxford: National Perinatal Epidemiology Unit, 2006.

19. Renfrew MJ, McFadden A, Dykes F, et al. Addressing the learning deficit in breastfeeding: strategies for change. Matern Child Nutr 2006; 2: 239-244.

20. National Collaborating Centre for Primary Care Postnatal care: routine postnatal care of women and their babies. NICE clinical guideline 37. London: RCOG Press, 2006.

21. Dyson L, Renfrew MJ, McFadden A, et al. Promotion of breastfeeding initiation and duration: evidence into practice briefing. London: National Institute for Health and Clinical Excellence, 2006.
22. Department of Health. Implementation plan for reducing health inequalities in infant mortality: a good practice guide. London: TSO, 2007

23. Healthcare Commission. Women's experiences of maternity care in the NHS in England. Key findings from a survey of NHS trusts carried out in 2007. London: Commission for Healthcare Audit and Inspection, 2007.

24. National Collaborating Centre for Women's and Children's Health. Antenatal care: routine care for the healthy pregnant women. NICE clinical guideline 6. London: RCOG Press, 2003.

DOI: 10.3399/bjgp08X277249

ADDRESS FOR CORRESPONDENCE

\section{Mary J Renfrew}

Professor of Mother and Infant Health, Department of Health Sciences,

University of York, Area 4,

Seebohm Rowntree Building,

Heslington, York YO10 5DD

E-mail: mjr505@york.ac.uk

\section{Heavy menstrual bleeding: delivering patient-centred care}

The last decades of the 20th century saw rising rates of surgery for heavy menstrual bleeding with associated high costs and morbidity. ${ }^{1,2}$ GPs have been implicated as contributing to this as referral rates vary widely between practices and high referral rates are significantly associated with high operative rates. ${ }^{3}$ GPs have also been criticised for being dismissive of menstrual problems and not addressing patients' concerns. ${ }^{4}$ A NICE guideline has been published recently which could lead to better primary care management of heavy menstrual bleeding and improve patients' quality of life. ${ }^{5}$

In the past, heavy menstrual bleeding has been defined in terms of volume of menstrual blood loss. ${ }^{6}$ However, volume of loss is not routinely measured in clinical practice and there is a poor correlation between measured loss and women's perceptions of their blood loss. ${ }^{7}$ It was thought that psychological problems could explain the lack of correlation between measured and perceived blood loss, but we now know that the relationship between heavy menstrual bleeding and psychiatric illness is no different to the relationship between psychiatric illness and other physical symptoms. ${ }^{8}$ There are several alternative explanations. Firstly, for individual women a change in volume of loss may be more significant than absolute volume of loss, for instance in leading to concern that something might be wrong or in challenging menstrual concealment strategies. ${ }^{4,9}$ Secondly, women's ability to contain heavy loss depends on their social circumstances; for example, women in jobs without easy access to toilets may have particular difficulty in managing heavy menstrual loss. ${ }^{10}$ Finally, it has been shown that the presence of other menstrual symptoms, such as pain, mood changes, and irregular bleeding all influence the impact of heavy menstrual bleeding. ${ }^{9,11}$

Clinicians may remain concerned that by focusing on the impact of symptoms rather than attempting to objectively assess volume of menstrual loss they may be missing significant underlying pathology. The NICE guideline provides a thorough summary of the epidemiology of uterine pathology. It highlights that although there is a lack of research in primary care, studies from secondary care show that the association between fibroids and heavy menstrual bleeding is less strong than previously thought. Furthermore, persistent intermenstrual bleeding is probably a more significant symptom than heavy menstrual bleeding in predicting endometrial cancer and this is very uncommon in women aged less than 45 years.

The NICE guideline provides a useful new definition of heavy menstrual bleeding based on impact on quality of life rather than measured blood loss:

'Heavy menstrual bleeding should be defined as excessive menstrual blood loss which interferes with the woman's physical, emotional, social, and material quality of life, and which can occur alone or in combination with other symptoms. Any interventions should aim to improve quality of life measures. ${ }^{5}$

The implication of this new definition is that clinicians should focus primarily on assessing the impact on daily life, rather than on notions around assessing volume of loss. Focusing on the impact of heavy menstrual bleeding addresses patients' concerns and should lead to more patient-centred care. The NICE guideline dealt only with heavy menstrual bleeding rather than other menstrual symptoms (such as menstrual 